\title{
Design of the Information Sharing Mechanism in Supporting Students' Collaborative Learning in PBL Environment
}

\author{
Yueh Hsiu-Ping \\ Department of Agricultural Extension, \\ National Taiwan University \\ Academic Center for Computing \& Media \\ Studies, Kyoto University \\ yueh@ntu.edu.tw
}

\author{
Lin Wei-Jane \\ Department of Intelligence Science \& \\ Technology, Kyoto University \\ lin@mm.media.kyoto-u.ac.jp
}

\begin{abstract}
The purpose of this study is to describe the design of the information sharing mechanism in online problem-based learning environment. Problem-based learning engages learners in collaborative and authentic learning experiences, knowledge and skills are inquired and acquired by collaboration of groups of learners. With the infusion of web-based technology, this study developed the information sharing mechanism to meet learners' needs of exchanging resources and opinions during the process of collaboration. This mechanism is an open, dynamic and evolving resources pool composed of instruction resources, group-gathering materials and personal learning references. Learners are able to easily give and get information within groups, and also contribute resources for the specific subject of the course.
\end{abstract}

\section{Introduction}

Problem-based learning (PBL) as a pedagogy is emphasized in education and training fields of researches for its capacity of motivating and facilitating learning activities. In the inquiry of problems, needs of gathering information, exchanging opinions and resources to support group decisions and understanding of the problem are highly demanded from groups of learners. Web technologies allow the possibility of sharing and exchanging information via various formats such as forums, bulletin board systems or even online concept mapping programs. However, what appeared to be neglected is, in the group learning environment, information sharing process composes not only personal interaction among students, but also interactions within and among groups, or even among the whole members including instructors, tutors and learners. Therefore, the mechanism of information sharing in problem-based learning environment is designed and developed in this study, targets the needs of multiple ways of information sharing and to facilitate learners' ability to understand the problem with better technology for information organization.

\section{Rationale of problem-based learning}

Problem-based learning puts students in a real world situation and expects them to find out the problems they are interested. In order to better understand the problem phenomena, it is necessary for students to gather and integrate various data and information to construct their conception of the problem. Barrow's approach to problem-based learning, which is thought as carefully designed and highly structured [3], also emphasized the importance of gathering and revising information items in facilitating reasoning through the PBL process [1]. (See figure 1). Learners encountered the problem first, during the process of PBL would experience the interactive process of identifying learning needs, and need to self-study to gain new knowledge, and finally apply the knowledge to solve the problem. At the end of PBL process, learners' summarization of what they have learned in the process is emphasized with the presentation of their learning outcome.

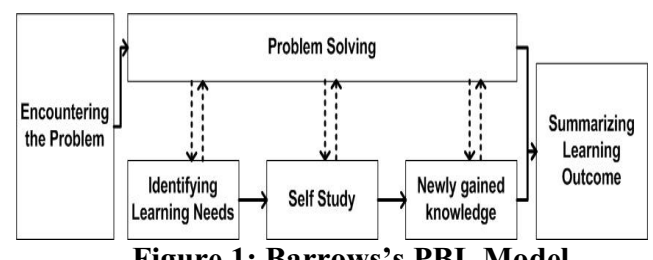

Figure 1: Barrows's PBL Model

Within the belief of constructivism, researchers have suggested several features of an ideal problem- 
based learning environment, such as empowering learners ownership of the process in developing solutions, encouraging testing ideas against alternative views and contexts[2], and providing opportunities for and support reflections on both the content learned and the learning process [3], which reflected the important role of sharing information in group learning and collaboration process.

\section{Technology of information sharing in problem-based learning}

With the web technologies development, users can exchange their personal opinions, upload files or documents, and even share programs between two computers simultaneously. The study tries to design an information sharing mechanism to utilize the existing personal sharing technology for group sharing and collaboration process in problem-based learning, which emphasizes the functions of revising, assessing and selecting information and to help students organize what they have gathered. In sum, the information sharing mechanism developed in this study extends existing web-based sharing technologies in the following two ways:

a) The design mainly targets the group learning and collaboration facilitation in the problem-based learning process. Therefore, all information gathered is automatically corresponsive to every phase of problem-based learning.

b) All the information and resources opened to share by individual group would be amounted together with consistent format. Learners are able to exchange information in multiple paths, within and among groups and all members in the class.

\section{Design of the information sharing mechanism in problem-based learning}

Two kinds of information sharing mechanisms are designed and developed in this study. The first one is about the general information. The second is about the specific data gathering for inquiring problem and clarifying learning needs.

At the beginning of problem-based learning, students will explore and decide the topics of interests. Constructing the consent of problem topics is very important for groups of learners to arrange their schedule of problem-solving, and also to establish positive group dynamics and clarify responsibilities of each member. This study develops the General Information Sharing mechanism for group members to share and gather information for discussion. The format of information for sharing includes multiple subjects and media; learners could also give brief introductions, reflections and ranks toward the item they shared. Those media students usually share are web-based resources, newspaper reports and magazine articles, probes readings, pictures and even videos.

After learners decide the topic of interest, they will begin the problem reasoning process following the hypotheses-facts-issues-action plan flow [2] shown as figure 2 .

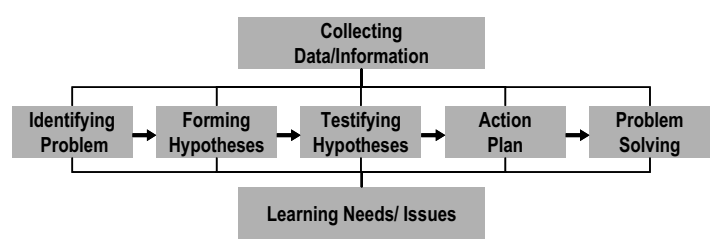

Figure 2. Problem-based Learning Process

During the PBL process, students need to collect a great amount of information as the resources for the problem inquiry, hypotheses testify, and action plan proposal. Group members need to review and revise the information back and forth for better understanding of the problem scenario and identifying the problem. The information collected by group members provided the evidence and reference for group's decision making to go through each step. Group discussions help learners share and test their ideas which is an essential process for problem solving. Therefore, this study designed the second information sharing mechanism, for students to easily come up with a group data collection workbench with a systematic way of information sharing and organization. Also, every group could open their workbench to be shared with different group members in the class.

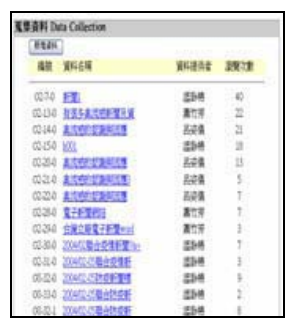

Figure 4 showed the item number, name, posting and review time of each data shared by group of learners.

Figure 3. Group Data Collection List

When one of the group members collect the related information about group's problem, he or she follows the same procedure as General Information Sharing to post this item of information on the Data Collection list of his/her own group. At the same time, the system 
recognizes and numbers this item of data by group's name, posting and revision time. (See Figure 3) Therefore, every item of information would be kept in a very systematic way and groups of learners can further modify the content of the information without messing up the database. This design feature is to ensure group members can still review all information of different versions along with the problem-solving process.

The second design feature of Data Collection is the sharing among groups. When groups of learners want to share their collection with other group members, they could easily identify the information and open it then the information will automatically be amounted in the Class Data Collection List as a resources repository for sharing.

The third design feature of Data Collection is the correspondence to problem-based learning process. Along with the data collection and sharing process, learners can identify information with specific steps of problem-based learning. Once the relevance between information and PBL step is established, this item of information will show on the list of related resources of the specific PBL step assigned by learners. This design emphasizes the transformation from collected data to group problem-based learning resources to facilitate group's reasoning through the problem. Besides, groups of learners can easily cross refer their resources and problem-based learning records in every step of PBL process.

\section{The information sharing mechanism in supporting students' collaborative learning}

The design of the information sharing mechanism in this study intends to integrate the data manipulation processes such as group discussion, data collection, information sharing and resources review into single group workbench, to form the repository of group resources and knowledge. Based on the design, researchers of the study also conduct a formative evaluation to collect users' feedback regarding this innovative design of information sharing mechanism. Results of the evaluation show that most students give very high assertions to this mechanism because they think it helped them with well-structured scaffolding for both information gathering as well as group interaction. Although sometimes groups of learners might have different comprehension and interpretation toward single item of information, however, this mechanism improves their opinion exchange among groups and help learners in groups to clarify problems with efficient way of information sharing.

\section{Conclusion}

In this paper we have proposed a design framework for supporting students' collaborative learning by making use of technologies of the information sharing mechanism in problem-based learning. The backbone of this mechanism is an open, dynamic and evolving resources repository composed of instruction resources, group-gathering materials and personal learning references. Learners are able to navigate through various resources in learning the curriculum via sharing information within and among groups, and to gain better understanding of the relationships, issues, relevant information sources and people, thus enabling them to achieve more informed group discussions and high quality of collaborations.

The next step of this study is to implement further evaluation and analysis, to extend the scale of understand learners' group learning behaviors and attitudes toward the information sharing mechanism integrated with PBL curriculum. The complete problem-based learning system will be further developed and evaluated integrally for clarifying the effects of each single module toward problem-based learning.

\section{References}

[1] Barrows, H., Practice-based learning: Problembased learning applied to medical education. Springfield, Illinois, 1994

[2] Cunningham, D.J., Duffy, T.M. \& Knuth, R.A., The textbook of the future. In C. McKnight, A. Dillon, and J. Richardson, (Eds.), Hypertext: A Psychological Perspective. Horwood Publishing, London, 1993.

[3] Dabbagh, N., Jonassen, D.H., Yueh, H., \& Samouilova, M. "Assessing a problem-based approach to an introductory instructional design course: A case study." Performance Improvement Quarterly, 13(3), 2000, pp.60-83. 